\title{
A Big World in Small Grain: A Review of Natural Milk Kefir Starters
}

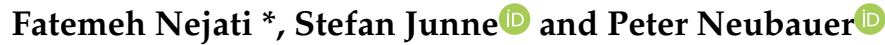 \\ Chair of Bioprocess Engineering, Institute of Biotechnology, Faculty III Process Sciences, Technische Universität \\ Berlin, Straße des 17. Juni 135, 10623 Berlin, Germany; stefan.junne@tu-berlin.de (S.J.); \\ peter.neubauer@tu-berlin.de (P.N.) \\ * Correspondence: f.nejati@tu-berlin.de; Tel.: +49-30-314-72521
}

Received: 20 December 2019; Accepted: 28 January 2020; Published: 30 January 2020

\begin{abstract}
Milk kefir is a traditional fermented milk product whose consumption is becoming increasingly popular. The natural starter for kefir production is kefir grain, which consists of various bacterial and yeast species. At the industrial scale, however, kefir grains are rarely used due to their slow growth, complex application, bad reproducibility and high costs. Instead, mixtures of defined lactic acid bacteria and sometimes yeasts are applied, which alter sensory and functional properties compared to natural grain-based milk kefir. In order to be able to mimic natural starter cultures for authentic kefir production, it is a prerequisite to gain deep knowledge about the nature of kefir grains, its microbial composition, morphologic structure, composition of strains on grains and the impact of environmental parameters on kefir grain characteristics. In addition, it is very important to deeply investigate the numerous multi-dimensional interactions among different species, which play important roles on the formation and the functionality of grains.
\end{abstract}

Keywords: lactic acid bacteria; milk kefir; consortia; identification; microbial interactions

\section{Introduction}

Milk kefir is an ancient fermented milk drink that originates from the Caucasus. It is widely used in human nutrition due to its health-promoting properties. Traditionally, kefir is produced by fermenting milk with kefir grains, which consist of a mixture of microbial species. Most of the milk kefir grains' habitants belong to the group of lactic acid bacteria (LAB), but kefir also contains yeasts and acetic acid bacteria (AAB). Depending on its age, the resulting kefir drink is typically acidic, of strong taste, partially viscous and fluffy [1].

For centuries, many health benefits were attributed to kefir, it was even consumed as a natural medicine [2]. Nutritional and medicinal properties of kefir have been in the focus of many scientific studies for decades. During milk fermentation by kefir grains, many functional compounds like bioactive peptides (e.g., with antihypertensive, antioxidative, antiallergenic, antitumor, antimicrobial, anti-inflammatory and cholesterol-lowering activities) [3,4], antimicrobial compounds (e.g., organic acids, alcohols, carbon dioxides and bacteriocins) and heteropolysaccharides (e.g., kefiran) with potential prebiotic activity are formed [5]. For a large number of kefir-isolated strains (e.g. Lactobacillus (Lb.) kefiranofaciens) and yeasts (e.g. Kluyveromyces (Kl.) marxianus), significant probiotic (probiotics are live microorganisms that, when administered in adequate amounts, confer a health benefit on the host) activities have been demonstrated in both in vitro and in vivo studies [6,7]. Based on these results, kefir is considered a "natural probiotic drink", which underlines its uniqueness among other fermented dairy products [8]. However, kefir-based sensory and functional properties are prone to a drastic change in microbiota, the peptide/protein profile, metabolites, if defined mixed cultures are used as starter cultures instead of kefir grains $[9,10]$. This review aims to summarize recent studies 
on milk kefir with an emphasis on the microbial composition, fine structure analysis and multi-layer interactions and their roles in kefir grains. It further highlights research opportunities and important issues for future studies in connection to the functionality of natural microbial kefir consortia and their integrity.

\section{Microbial Structure of Kefir}

The exact microbiological composition of kefir grains is still controversial. Up to 50 different bacterial and yeast species have been found in grain-based milk kefirs, which has been comprehensively reviewed elsewhere [11,12]. It seems that the geographical origin of the kefir samples (Table 1) and the cultivation conditions (e.g., different types of milk, temperatures, incubation times and ratios of grain and milk) may largely influence the microbial composition and dynamics of the kefir [13,14]. Nevertheless, the methods applied to identify this complex microbial community are not suitable to identify them correctly, as the results of microbial identification of the applied method influence by themselves (Table 1). For example, Kesmen and Kacmaz (2011) were able to identify Lactococcus (Lc.) lactis, Leuconostoc (L.) mesenteroides and $L b$. kefiri as prevalent bacteria species with culture-dependent methods, while PCR denaturing gradient gel electrophoresis (DGGE) as a culture-independent method identified Lb. kefiranofaciens and Lc. lactis as prevalent [15].

Combinations of both, culture-dependent and rather traditional culture-independent methods, e.g., DGGE of PCR amplicons of rRNA-targeted gene regions, were the most common methods for the identification of kefir microbiota for many years [16]. Later, however, studies have shown that these combinations have limitations and drawbacks to accurately assess microbial communities $[17,18]$. For example, the V3 region of the $16 \mathrm{~S}$ rRNA gene, which was widely used for the identification by rRNA-PCR-DGGE [15], cannot separate sufficiently closely related species like Lb. kefiri, Lb. buchneri, $L b$. sunkii and $L b$. otakiensis $[18,19]$. In contrast, newer identification techniques, like whole metagenome shotgun sequencing, provide more detailed information about the overall microbial structure, in particular for species of low abundance. These methods were able to provide a broader view on the microbial composition and population dynamics of kefir [20-22].

Table 1. Microbial composition of kefir samples of different geographical locations.

\begin{tabular}{|c|c|c|c|}
\hline $\begin{array}{c}\text { Geographic Location } \\
\text { of Studied Sample }\end{array}$ & Method of Analysis & Identified Bacteria or Yeasts & Reference \\
\hline $\begin{array}{l}\text { France, Ireland and the } \\
\text { United Kingdom }\end{array}$ & $\begin{array}{l}\text { Metagenomics (16S rRNA } \\
\text { and ITS sequencing) }\end{array}$ & $\begin{array}{l}\text { Lb. kefiranofaciens, Leuconostoc spp., } \\
\text { Lb. helveticus, A. pasteurianus, Saccharomyces } \\
\text { spp. and Kazachstania spp. }\end{array}$ & [23] \\
\hline Belgium & $\begin{array}{l}\text { Metagenomics ( } 16 \mathrm{~S} \text { and } \\
26 \mathrm{~S} \text { rRNA sequencing) }\end{array}$ & $\begin{array}{l}\text { Lb. kefiranofaciens or Lc. lactis, Lb. kefiri, } \\
\text { Acetobacter spp. and Enterobacter spp., } \\
\text { Kl. marxianus, Kz. exigua and } \\
\text { Nauvomozyma spp. }\end{array}$ & [22] \\
\hline Malaysia & $\begin{array}{c}\text { Metagenomics } \\
\text { (16S rRNA sequencing) }\end{array}$ & Lb. kefiranofaciens and Lb. kefiri & {$[20]$} \\
\hline Italy & $\begin{array}{l}\text { Metagenomics (16S rRNA } \\
\text { and } 26 S \text { rRNA sequencing) }\end{array}$ & $\begin{array}{l}\text { Lb. kefiranofaciens as dominant and Lb. kefiri, } \\
\text { Enterococcus spp., Lc. lactis and Acetobacter } \\
\text { spp. as subdominant bacteria, Dekkera } \\
\text { anomalus, Kz. exigua, S. cerevisiae }\end{array}$ & [18] \\
\hline \multirow[b]{2}{*}{ Brazil } & PCR-DGGE & Lb. kefiranofaciens and L. kefiri & \multirow[b]{2}{*}{ [17] } \\
\hline & $\begin{array}{c}\text { Metagenomics } \\
\text { (16S rRNA sequencing) }\end{array}$ & $\begin{array}{l}\text { Lactobacillus spp., such as } L b \text {. kefiranofaciens } \\
\text { subsp. kefirgranum, and subsp. } \\
\text { kefiranofaciens, Lb. kefiri, Lb. parakefiri, } \\
\text { Lb. parabuchneri, Lb. amilovorus, Lb. crispatus } \\
\text { and Lb. buchneri }\end{array}$ & \\
\hline
\end{tabular}


Table 1. Cont.

\begin{tabular}{|c|c|c|c|}
\hline $\begin{array}{l}\text { Geographic Location } \\
\text { of Studied Sample }\end{array}$ & Method of Analysis & Identified Bacteria or Yeasts & Reference \\
\hline Turkey & $\begin{array}{c}\text { Metagenomics } \\
\text { (16S rRNA sequencing) }\end{array}$ & Lb. kefiranofaciens, Lb. buchneri, Lb. helveticus & [19] \\
\hline \multirow[t]{2}{*}{ Turkey } & PCR-DGGE & $\begin{array}{l}\text { Lb. kefiranofaciens, Lb. kefiri, Lb. buchneri, } \\
\text { Lb. sunkii, Lb. otakiensis }\end{array}$ & [15] \\
\hline & Culture dependent & Lc. lactis, L. mesenteroides, Lb. kefiri & \\
\hline Russia & Culture dependent & $\begin{array}{l}\text { Lb. kefiranofaciens, Lb. kefiri, Lb. parakefiri, } \\
\text { Lc. lactis and Leuconostoc spp. }\end{array}$ & [24] \\
\hline
\end{tabular}

Although it seems that there is a big difference in the microbial composition among kefirs of different origins, the microbial composition, or at least dominant species, of kefir does not necessarily have to be complex. As an example, Wang et al. showed that $L b$. kefiranofaciens is the only dominant bacterial species in Tibetan milk kefir grains independent of kefir production conditions by applying DGGE and metagenomic analysis [25]. According to several studies, just a few species, like $L b$. kefiranofaciens (both subsp. kefiranofaciens and subsp. kefirgranum) and Lb. kefiri are ubiquitous, in which $L b$. kefiranifaciens is homofermentative (lactic acid as the main end product), while Lb. kefiri is heterofermentative (producer of lactic acid, acetic acid, and carbon dioxide) [11,24]. The ratio of homofermentative to heterofermentative LAB has also been considered as a sensitive parameter in studies about microbial populations in kefir and its grain stability. Takizawa et al. observed that $90 \%$ of the total population of a kefir consisted of homofermentative bacteria (mainly of Lb. kefiranofaciens) [26], while Vardjan et al. found a ratio of homofermentative ( $L b$. kefiranofaciens subsp. kefirgranum) to heterofermentative ( $L b$. kefiri and $L b$. parakefiri) species of about 1:1, which remained stable over four months [27]. The results of such culture-dependent studies, however, highly depend on the medium and conditions during species isolation. Additionally, plate counting for the quantification of viable cells is usually prone to a high variability.

\section{Microbiota vs. Functional Properties}

The single knowledge about the microbial composition of a community is not enough to understand the way each species or strain contributes to the formation of functional properties. Microbial communities are usually known as stable systems with mutual interactions between the different metabolic networks [8]. In order to achieve similar features in synthetic microbial consortia for industrial application, it is necessary to gain a deeper understanding of the allocated functions within the consortia and of the relation between microbiota and process performance.

'Omics' technologies (i.e., genomics, transcriptomics, proteomics and metabolomics) are powerful approaches to characterize the behavior of complex food consortia during the course of a fermentation $[28,29]$. Applying these comprehensive analyses allows the identification of the microorganisms(s) that play leading roles within the community [30,31]. For example, by the combination of metagenomics (to study the microbial dynamics) and metabolomics (to monitor the development of flavor compounds), it was observed that $L b$. kefiranofaciens was the dominant microorganism in the early stages of milk kefir fermentation, while L. mesenteroides became more prevalent in later fermentation stages, which was correlated to concentration changes of volatile compounds [23].

Although there are still some limitations and challenges in design, application and data interpretation of omic-based analyses [32], it is obvious that they hold great potential to improve our understanding of microbial communities. The results of such studies are very helpful for the selection of most suitable strains to design artificial consortia or functional mixed starters [30]. 


\section{Generation of Kefir Grains}

The physical structure of kefir grains and the arrangement of microbiota within this structure is an important issue for the understanding of the microbiota's functions and potential interactions within the consortia. Kefir grains exhibit an irregular cauliflower-like shape which consists of numerous hollow globular structures with a usual diameter of 2.0 to $9.0 \mathrm{~mm}$, whereby the globules form a polyhedral network structure [33]. The matrix is composed of the exopolysaccharide kefiran, proteins, microbial cell debris and other materials, which were not specified so far $[33,34]$. The arrangement of microbiota on or in this structure is still a matter of research. Although some studies show that the microorganisms occupy all interior and exterior surfaces of grains [34,35], bacteria are hardly observed on the outer surfaces of grains, but only embedded in the fibrillar matrix near the surface [36]. It is very likely that the variations in grain cultivation conditions and environmental parameters caused these different observations about the arrangement of microbiota. Additionally, cell sizes and chain lengths can differ, in respect to physiological stages or external stresses (e.g., cultivation conditions and limitation of available nutrients), which may lead to false interpretations of microscopy data of microbial communities. For instance, $L b$. kefiranofaciens was observed in two distinct morphotypes of short (3.0 $\mu \mathrm{m}$ in length) and long $(10.0 \mu \mathrm{m}$ in length) rods that have colonized either on the outer surfaces or inner surfaces of kefir grains [25].

It is unclear what causes the microbiota of kefir to form such a stable consortium that maintains its functionality for an infinite time. So far, all attempts to generate de novo kefir grain in any fermentation of mixtures of pure starter cultures have failed [37].

There are a few hypotheses, however, about the mechanisms involved in the formation of grains. It is assumed that the initial auto- and co-aggregation of lactobacilli and yeasts are the main initiating phenomena of the formation of small granules [11]. According to Wang et al., grain formation begins with self-aggregation of $L b$. kefiranofaciens and Kazachstania (Ka.) turicensis [35]. Then, biofilm producing species like $L b$. kefiri attach to the surface of the granules and co-aggregate with other microorganisms and milk components to form larger granules and probably kefir grains. Recently, the role of AAB like Acetobacter (A.) orientalis has been studied [34]. It seems that LAB and AAB are responsible for polysaccharide production and biofilm formation, while yeasts play a role in the evolvement of complex networks between the three microbes [34].

It is worth to mention that the occurrence of such inter-microbial interactions is highly strain specific. For example, it was observed that only six out of $20 \mathrm{Lb}$. kefiri strains were able to co-aggregate with Saccharomyces (S.) lipolytica strains, albeit all strains were isolated from kefir [38].

\section{Inter-Microbial Interactions}

Compared to a single taxon, microbial assemblages have proven to be highly resilient under adverse conditions and flexible in terms of substrate conversion [39]. These outstanding properties can be due to the participation of different microorganisms, wherein each of them carries its own specific genetic material and shares its metabolic features with others in the community. Although strong interaction is essential for achieving robustness in many ecological systems, the complexity increases with the number of microorganisms that are involved in a community [40]. Thus, studies become more difficult. In any kind of microbial community, microbial interactions can be studied from two aspects: (1) The nature of interactions and (2) the participating members.

\subsection{Nature of Interactions}

Species, as members of a community, typically influence each other's growth and metabolism in several modes [41]. Interactions can be classified in two groups: (i) Direct, through physical contacts, and (ii) Indirect, either through the excretion of signal molecules (inhibitors/stimulators) or changing environmental growth factors (like $\mathrm{pH}$ and gas composition) [42]. 
Direct or physical interactions: In many cases, direct interactions and cell to cell attachments enable microorganisms to work cooperatively and form complex structures like a biofilm [43,44], which usually leads to an increased viability of the microbial community members and their resistance to stresses. For example, S. cerevisiae can significantly enhance the viability of the probiotic strain Lb. rhamnosus HN001 under acidic conditions [45]. Microscopic observations revealed that this effect is due to the direct cell to cell contact and subsequent co-aggregation that is mediated by yeast cell wall polysaccharides and bacterial cell surface proteins [38,46]. Mendes et al. reported the direct interaction between $S$. cerevisiae and $L b$. delbrueckii as a strategy to cope with the adverse conditions at a low $\mathrm{pH}$ and in the presence of ethanol [47]. Cheirslip et al. showed the importance of the physical interactions between two kefir inhabitants, S. cerevisiae and $L b$. kefiranofaciens, for enhanced production of exopolysaccharide kefiran by Lb. kefiranofaciens [48]. Exopolysaccharide kefiran is one of the main components of milk kefir grain.

Indirect interactions: Primary and secondary extracellular metabolites have significant impacts on other partners of the community. Johansen et al. reviewed the functions of several quorum sensing (QS) (mediation of microbial cell-cell communication by secretion or recognition of small signal molecules) systems to regulate microbial traits in food-related communities and the potential effects on the quality of fermented products [49]. QS has been studied for several microorganisms involved in the production of fermented vegetables, sourdough, wine and some dairy products [50-53]. Although there are recent studies about the analysis of the metabolites profile of milk kefir [54-56], there is no thorough study to investigate the signaling functions of such metabolites on kefir-related species.

\subsection{Participating Members}

Relevant types of interactions within a kefir community can be categorized as follows:

- Yeast-Bacteria Interactions

The interaction between yeasts and LAB is central in a wide range of fermented foods, in particular in kefir [44]. Both groups of microorganisms naturally support each other in different ways:

I. Assimilation of lactic acid: One interesting mechanism of interaction between yeasts and $\mathrm{LAB}$ is conducted in the presence of lactic acid assimilating-yeasts. Accumulation of lactic acid injures and kills LAB even when the $\mathrm{pH}$ of the culture is maintained by the addition of alkaline solutions [57]. However, lactic acid can be consumed as a carbon source by non-lactose-consuming yeasts, such as S. cerevisiae, which results in an increased $\mathrm{pH}$ and a prolonged growth of lactobacilli. This cooperation has been reported to strongly enhance production of the capsular kefiran by Lb. kefiranofaciens [48,58].

II. Production of $\mathrm{CO}_{2} /$ removal of $\mathrm{O}_{2}$ : Carbon dioxide can provide a suitable atmosphere (reduced oxygen and elevated $\mathrm{CO}_{2}$ ) to favor Lactobacillus spp. growth. Even though no studies are available about kefir-isolated microorganisms, studies about other communities and food-isolated microorganisms verify this interaction. Suharja et al. linked the enhanced viability of probiotic $L b$. rhamnosus to oxygen scavenging activity of S. cerevisiae [59]. A similar mechanism has been observed between $L b$. sanfranciscensis and S. cerevisiae, two isolates of sourdough microbiota [60].

III. Providing nutrients to bacteria: Trophic interactions and exchange of metabolites (cross-feeding) enable multiple groups of microorganisms to survive on limited resources. Yeast species have been shown to serve bacteria by providing vitamins, growth factors and essential amino acids [61]. Sadie et al. observed that Zygotorulaspora florentina excretes essential amino acids that support $L b$. nagelii growth when they are co-cultivated, but not if they are cultivated as monoculture [62].

For exploring details of metabolite cross-feeding between $S$. cerevisiae and two species of LAB (Lb. plantarum or Lc. Lactis) in model systems, Ponomarova et al. used combined metabolomics and 
genetic tools [61]. They demonstrated how nitrogen overflow by yeast contributes to the emergence of mutualism with Lc. Lactis. Mutualism between Lc. lactis and S. cerevisiae easily emerges when lactose is the main carbon source. This finding highlights again the fact that the composition of the growth medium has an important role on the formation of inter-species interactions.

\section{- Bacteria-Bacteria Interactions}

Food-related bacteria-bacteria interactions have not been studied to the same extent as yeast-bacteria interactions. There are informative studies on bacteria-bacteria interactions between bacterial species of yogurt, Lb. delbrueckii subsp. bulgaricus and Streptococcus (S.) thermophilus, which are known for their protocooperative and symbiotic interactions [41]. When grown together, Lb. delbrueckii subsp. bulgaricus encoding the hydrophobic di/tripeptides Dpp transport system, which is complemented by the general di/tripeptide DtpT transporter system in S. thermophilus. This interaction results in the utilization of more peptides by both bacteria [63]. In a recent study, interactions between several kefir bacterial species (e.g., Lb. kefiranofaciens, Lb. kefir, Lc. lactis. A. fabarum and L. mesenteroides) in pairwise combinations have been the topic of investigation and a more detailed layer has been added to the knowledge of kefir-related microbiota interactions [54]. According to this study, Lb. Kefiranofaciens, a ubiquitous strain of kefir microbiota, suppressed growth of its direct competitor Lb. kefiri, while promoting growth of L. mesenteroides and having no effect on Lc. lactis and A. fabarum.

- Yeast-Yeast Interactions

Communication among yeasts through QS is not as well documented. In some food ecosystems like wine and sourdough, some studies have been carried out to identify metabolites and conditions involved in QS communication in the model yeast S. cerevisiae [53]. These show environmental factors, like the nitrogen content in the medium, cell density, aerobic/anaerobic conditions and ethanol content affect profoundly the production of QS-related molecules by S. cerevisiae [64]. For example, yeasts QS-related molecules like aromatic alcohols (e.g., tryptophol, tyrosol and 2-phenylethanol) are secreted at highest rates when the ammonium sulfate concentration is below $50 \mu \mathrm{M}$. These rates are reduced when the ammonium sulfate concentration raises above $500 \mu \mathrm{M}$ [49]. Interestingly, such QS-related aromatic molecules are applied also as antioxidant or antimicrobial agents and are used in quality control assessments [64].

Some strains of $S$. cerevisiae secrete peptides that inhibit the growth of some non-Saccharomyces strains, such as Kl. marxianus [65]. This characteristic is reported to be highly strain-dependent [66]. As S. cerevisae, Kl. marxianus and Kazachstania spp. (Kz. turicensis, Kz. unispora and Kz. exigua) are important yeast species of kefir microbial community $[18,44,54]$, unravelling of the interactions among these species and the relation to kefir quality and grains functionalities are very important.

\section{Effects of External Parameters on Kefir Robustness and Integrity}

Environmental changes during any fermentation lead to harsh stress on microorganisms, so that survival under the newly developed conditions depends highly on stress response mechanisms. The inhabitants of kefir grains are also confronted with several stress factors during milk fermentation (such as high acidity, rapid temperature fluctuations, limitation of nutrients, presence of antimicrobial compounds, etc.) and not only during a single fermentation, but also during successive fermentations. Each can affect the population dynamics drastically [67]. Vardjan et al. [68] however, demonstrated that the prevailing lactobacilli and yeasts in kefir grains and kefir beverages are stable during ten weeks of propagation. It has not been investigated decently which parameters are responsible for the protection of the kefir microbiota against successive environmental stresses. Investigation of Lb. kefiranofaciens M1 stress adaptation under lethal and sub-lethal levels of heat, cold, acid and bile salt stresses shows up-regulating of several classes of proteins belong to carbohydrate metabolism (TpiA, ENO and GPDH), pH homeostasis (AtpA and AtpB), stress response proteins (DnaK and GroEL) and translation-related protein (Rps2) [69]. Despite the importance of this subject, the knowledge how 
about kefir grain microbiota cope with stresses is very limited. What are the roles of inter-species interactions in stress adaptation, is something that is worth being studied.

\section{Conclusions}

The purpose of this review was to summarize the latest findings in grain-based milk kefir studies and lighten up possible fundamental research that is required to define parameters of robustness and integrity of kefir grains. This knowledge can be helpful for developing fully functional artificial starter cultures for increased quality attributes and consumer acceptance for industrial application.

Author Contributions: Conceptualization, F.N., P.N.; writing-original draft preparation, F.N.; writing-review and editing, P.N., S.J. All authors have read and agreed to the published version of the manuscript.

Funding: F.N. was supported by Einstein foundation (MICROBALANCE project).

Conflicts of Interest: The authors declare no conflict of interest.

\section{References}

1. Kabak, B.; Dobson, A.D.W. An Introduction to the Traditional Fermented Foods and Beverages of Turkey. Crit. Rev. Food Sci. Nutr. 2011, 51, 248-260. [CrossRef] [PubMed]

2. Rosell, J.M. Yoghourt and kefir in their relation to health and therapeutics. Can. Med. Assoc. J. 1932, 26, 341-345. [PubMed]

3. Amorim, F.G.; Coitinho, L.B.; Dias, A.T.; Friques, A.G.F.; Monteiro, B.L.; de Rezende, L.C.D.; Pereira, T.D.M.C.; Campagnaro, B.P.; De Pauw, E.; Vasquez, E.C.; et al. Identification of new bioactive peptides from Kefir milk through proteopeptidomics: Bioprospection of antihypertensive molecules. Food Chem. 2019, 282, 109-119. [CrossRef] [PubMed]

4. Cotârleț, M.; Vasile, A.M.; Cantaragiu, A.M.; Gaspar-Pintiliescu, A.; Crăciunescu, O.; Oancea, A.; Moraru, A.; Moraru, I.; Bahrim, G.E. Colostrum-derived bioactive peptides obtained by fermentation with kefir grains enriched with selected yeasts. Ann. Univ. Dunarea Jos Galati Fascicle VI-Food Technol. 2019, 43, 54-68. [CrossRef]

5. Kim, D.-H.; Jeong, D.; Kim, H.; Seo, K.-H. Modern perspectives on the health benefits of kefir in next generation sequencing era: Improvement of the host gut microbiota. Crit. Rev. Food Sci. Nutr. 2019, 59, 1782-1793. [CrossRef]

6. Yamane, T.; Sakamoto, T.; Nakagaki, T.; Nakano, Y.; Yamane, T.; Sakamoto, T.; Nakagaki, T.; Nakano, Y. Lactic Acid Bacteria from Kefir Increase Cytotoxicity of Natural Killer Cells to Tumor Cells. Foods 2018, 7, 48. [CrossRef]

7. Xing, Z.; Tang, W.; Geng, W.; Zheng, Y.; Wang, Y. In vitro and in vivo evaluation of the probiotic attributes of Lactobacillus kefiranofaciens XL10 isolated from Tibetan kefir grain. Appl. Microbiol. Biotechnol. 2017, 101, 2467-2477. [CrossRef]

8. Garrote, G.L.; Abraham, A.G.; De Antoni, G.L. Microbial Interactions in Kefir: A Natural Probiotic Drink. In Biotechnology of Lactic Acid Bacteria: Novel Applications; Mozzi, F., Raya, R.R., Vignolo, G.M., Eds.; Blackwell Publishing: Iowa, IA, USA, 2010; ISBN 0813820952.

9. Assadi, M.M.; Pourahmad, R.; Moazami, N. Use of isolated kefir starter cultures in kefir production. World J. Microbiol. Biotechnol. 2000, 16, 541-543. [CrossRef]

10. Lee, B.; Yi, H.-C.; Moon, Y.-I.; Oh, S. Development of a Functional Mixed-Starter Culture for Kefir Fermentation. J. Milk Sci. Biotechnol. 2018, 36, 178-185. [CrossRef]

11. Prado, M.R.; Blandón, L.M.; Vandenberghe, L.P.S.; Rodrigues, C.; Castro, G.R.; Thomaz-Soccol, V.; Soccol, C.R. Milk kefir: Composition, microbial cultures, biological activities, and related products. Front. Microbiol. 2015, 6, 1177. [CrossRef]

12. Bourrie, B.C.T.; Willing, B.P.; Cotter, P.D. The Microbiota and Health Promoting Characteristics of the Fermented Beverage Kefir. Front. Microbiol. 2016, 7, 647. [CrossRef] [PubMed]

13. Barão, C.E.; Klososki, S.J.; Pinheiro, K.H.; Marcolino, V.A.; Junior, O.V.; da Cruz, A.G.; da Silva, T.T.; Pimentel, T.C. Growth kinetics of kefir biomass: Influence of the incubation temperature in milk. Chem. Eng. Trans. 2019, $75,499-504$. 
14. Gul, O.; Mortas, M.; Atalar, I.; Dervisoglu, M.; Kahyaoglu, T. Manufacture and characterization of kefir made from cow and buffalo milk, using kefir grain and starter culture. J. Dairy Sci. 2015, 98, 1517-1525. [CrossRef] [PubMed]

15. Kesmen, Z.; Kacmaz, N. Determination of Lactic Microflora of Kefir Grains and Kefir Beverage by Using Culture-Dependent and Culture-Independent Methods. J. Food Sci. 2011, 76, M276-M283. [CrossRef] [PubMed]

16. Chen, H.-C.; Wang, S.-Y.; Chen, M.-J. Microbiological study of lactic acid bacteria in kefir grains by culture-dependent and culture-independent methods. Food Microbiol. 2008, 25, 492-501. [CrossRef] [PubMed]

17. Leite, A.M.O.; Mayo, B.; Rachid, C.T.C.C.; Peixoto, R.S.; Silva, J.T.; Paschoalin, V.M.F.; Delgado, S. Assessment of the microbial diversity of Brazilian kefir grains by PCR-DGGE and pyrosequencing analysis. Food Microbiol. 2012, 31, 215-221. [CrossRef]

18. Garofalo, C.; Osimani, A.; Milanović, V.; Aquilanti, L.; De Filippis, F.; Stellato, G.; Di Mauro, S.; Turchetti, B.; Buzzini, P.; Ercolini, D.; et al. Bacteria and yeast microbiota in milk kefir grains from different Italian regions. Food Microbiol. 2015, 49, 123-133. [CrossRef]

19. Nalbantoglu, U.; Cakar, A.; Dogan, H.; Abaci, N.; Ustek, D.; Sayood, K.; Can, H. Metagenomic analysis of the microbial community in kefir grains. Food Microbiol. 2014, 41, 42-51. [CrossRef]

20. Zamberi, N.R.; Mohamad, N.E.; Yeap, S.K.; Ky, H.; Beh, B.K.; Liew, W.C.; Tan, S.W.; Ho, W.Y.; Boo, S.Y.; Chua, Y.H.; et al. 16S Metagenomic Microbial Composition Analysis of Kefir Grain using MEGAN and BaseSpace. Food Biotechnol. 2016, 30, 219-230. [CrossRef]

21. Gao, W.; Zhang, L. Comparative analysis of the microbial community composition between Tibetan kefir grains and milks. Food Res. Int. 2019, 116, 137-144. [CrossRef]

22. Korsak, N.; Taminiau, B.; Leclercq, M.; Nezer, C.; Crevecoeur, S.; Ferauche, C.; Detry, E.; Delcenserie, V.; Daube, G. Short communication: Evaluation of the microbiota of kefir samples using metagenetic analysis targeting the 16S and 26S ribosomal DNA fragments. J. Dairy Sci. 2015, 98, 3684-3689. [CrossRef] [PubMed]

23. Walsh, A.M.; Crispie, F.; Kilcawley, K.; O'Sullivan, O.; O'Sullivan, M.G.; Claesson, M.J.; Cotter, P.D. Microbial Succession and Flavor Production in the Fermented Dairy Beverage Kefir. mSystems 2016, 1, e00052-16. [CrossRef] [PubMed]

24. Mainville, I.; Robert, N.; Lee, B.; Farnworth, E.R. Polyphasic characterization of the lactic acid bacteria in kefir. Syst. Appl. Microbiol. 2006, 29, 59-68. [CrossRef] [PubMed]

25. Wang, X.; Xiao, J.; Jia, Y.; Pan, Y.; Wang, Y. Lactobacillus kefiranofaciens, the sole dominant and stable bacterial species, exhibits distinct morphotypes upon colonization in Tibetan kefir grains. Heliyon 2018, 4, e00649. [CrossRef] [PubMed]

26. Takizawa, S.; Kojima, S.; Tamura, S.; Fujinaga, S.; Benno, Y.; Nakase, T. The Composition of the Lactobacillus Flora in Kefir Grains. Syst. Appl. Microbiol. 1998, 21, 121-127. [CrossRef]

27. Vardjan, T.; Mohar Lorbeg, P.; Rogelj, I.; Čanžek Majhenič, A. Characterization and stability of lactobacilli and yeast microbiota in kefir grains. J. Dairy Sci. 2013, 96, 2729-2736. [CrossRef]

28. Bertuzzi, A.S.; Walsh, A.M.; Sheehan, J.J.; Cotter, P.D.; Crispie, F.; McSweeney, P.L.H.; Kilcawley, K.N.; Rea, M.C. Omics-Based Insights into Flavor Development and Microbial Succession within Surface-Ripened Cheese. mSystems 2018, 3. [CrossRef]

29. Walsh, A.M.; Crispie, F.; Claesson, M.J.; Cotter, P.D. Translating Omics to Food Microbiology. Annu. Rev. Food Sci. Technol. 2017, 8, 113-134. [CrossRef]

30. McAuliffe, O.; Kilcawley, K.; Stefanovic, E. Symposium review: Genomic investigations of flavor formation by dairy microbiota. J. Dairy Sci. 2019, 102, 909-922. [CrossRef]

31. Sirén, K.; Mak, S.S.T.; Fischer, U.; Hansen, L.H.; Gilbert, M.T.P. Multi-omics and potential applications in wine production. Curr. Opin. Biotechnol. 2019, 56, 172-178. [CrossRef]

32. Nilsson, R.H.; Anslan, S.; Bahram, M.; Wurzbacher, C.; Baldrian, P.; Tedersoo, L. Mycobiome diversity: High-throughput sequencing and identification of fungi. Nat. Rev. Microbiol. 2019, 17, 95-109. [CrossRef] [PubMed]

33. Lu, M.; Wang, X.; Sun, G.; Qin, B.; Xiao, J.; Yan, S.; Pan, Y.; Wang, Y. Fine Structure of Tibetan Kefir Grains and Their Yeast Distribution, Diversity, and Shift. PLoS ONE 2014, 9, e101387. [CrossRef] [PubMed]

34. Dong, J.; Liu, B.; Jiang, T.; Liu, Y.; Chen, L. The biofilm hypothesis: The formation mechanism of Tibetan kefir grains. Int. J. Dairy Technol. 2018, 71, 44-50. [CrossRef]

35. Wang, S.-Y.; Chen, K.-N.; Lo, Y.-M.; Chiang, M.-L.; Chen, H.-C.; Liu, J.-R.; Chen, M.-J. Investigation of microorganisms involved in biosynthesis of the kefir grain. Food Microbiol. 2012, 32, 274-285. [CrossRef] 
36. Ismaiel, A.A.; Ghaly, M.F.; El-Naggar, A.K. Milk Kefir: Ultrastructure, Antimicrobial Activity and Efficacy on Aflatoxin B1 Production by Aspergillus flavus. Curr. Microbiol. 2011, 62, 1602-1609. [CrossRef]

37. Kotova, I.B.; Cherdyntseva, T.A.; Netrusov, A.I. Russian kefir grains microbial composition and its changes during production process. In Advances in Experimental Medicine and Biology; Springer: Cham, Switzerland, 2016; Volume 932, pp. 93-121.

38. Golowczyc, M.A.; Mobili, P.; Garrote, G.L.; de los Angeles Serradell, M.; Abraham, A.G.; De Antoni, G.L. Interaction between Lactobacillus kefir and Saccharomyces lipolytica isolated from kefir grains: Evidence for lectin-like activity of bacterial surface proteins. J. Dairy Res. 2009, 76, 111-116. [CrossRef]

39. Padmaperuma, G.; Kapoore, R.V.; Gilmour, D.J.; Vaidyanathan, S. Microbial consortia: A critical look at microalgae co-cultures for enhanced biomanufacturing. Crit. Rev. Biotechnol. 2018, 38, 690-703. [CrossRef]

40. Magnúsdóttir, S.; Thiele, I. Modeling metabolism of the human gut microbiome. Curr. Opin. Biotechnol. 2018, 51, 90-96. [CrossRef]

41. Sieuwerts, S.; de Bok, F.A.M.; Hugenholtz, J.; van Hylckama Vlieg, J.E.T. Unraveling microbial interactions in food fermentations: From classical to genomics approaches. Appl. Environ. Microbiol. 2008, 74, 4997-5007. [CrossRef]

42. Zerfaß, C.; Chen, J.; Soyer, O.S. Engineering microbial communities using thermodynamic principles and electrical interfaces. Curr. Opin. Biotechnol. 2018, 50, 121-127. [CrossRef]

43. Furukawa, S.; Isomae, R.; Tsuchiya, N.; Hirayama, S.; Yamagishi, A.; Kobayashi, M.; Suzuki, C.; Ogihara, H.; Morinaga, Y. Screening of lactic acid bacteria that can form mixed-species biofilm with Saccharomyces cerevisiae. Biosci. Biotechnol. Biochem. 2015, 79, 681-686. [CrossRef] [PubMed]

44. Han, X.; Zhang, L.-J.; Wu, H.-Y.; Wu, Y.-F.; Zhao, S.-N. Investigation of microorganisms involved in kefir biofilm formation. Antonie Van Leeuwenhoek 2018, 111, 2361-2370. [CrossRef] [PubMed]

45. Lim, P.L.; Toh, M.; Liu, S.Q. Saccharomyces cerevisiae EC-1118 enhances the survivability of probiotic Lactobacillus rhamnosus HN001 in an acidic environment. Appl. Microbiol. Biotechnol. 2015, 99, 6803-6811. [CrossRef] [PubMed]

46. Xie, N.; Zhou, T.; Li, B. Kefir yeasts enhance probiotic potentials of Lactobacillus paracasei H9: The positive effects of coaggregation between the two strains. Food Res. Int. 2012, 45, 394-401. [CrossRef]

47. Mendes, F.; Sieuwerts, S.; de Hulster, E.; Almering, M.J.H.; Luttik, M.A.H.; Pronk, J.T.; Smid, E.J.; Bron, P.A.; Daran-Lapujade, P. Transcriptome-based characterization of interactions between Saccharomyces cerevisiae and Lactobacillus delbrueckii subsp. bulgaricus in lactose-grown chemostat cocultures. Appl. Environ. Microbiol. 2013, 79, 5949-5961. [CrossRef] [PubMed]

48. Cheirsilp, B.; Shoji, H.; Shimizu, H.; Shioya, S. Interactions between Lactobacillus kefiranofaciens and Saccharomyces cerevisiae in mixed culture for kefiran production. J. Biosci. Bioeng. 2003, 96, 279-284. [CrossRef]

49. Johansen, P.; Jespersen, L. Impact of quorum sensing on the quality of fermented foods. Curr. Opin. Food Sci. 2017, 13, 16-25. [CrossRef]

50. Huang, Z.-R.; Guo, W.-L.; Zhou, W.-B.; Li, L.; Xu, J.-X.; Hong, J.-L.; Liu, H.-P.; Zeng, F.; Bai, W.-D.; Liu, B.; et al. Microbial communities and volatile metabolites in different traditional fermentation starters used for Hong Qu glutinous rice wine. Food Res. Int. 2019, 121, 593-603. [CrossRef]

51. Das, S.; Deb, D.; Adak, A.; Khan, M.R. Exploring the microbiota and metabolites of traditional rice beer varieties of Assam and their functionalities. 3 Biotech 2019, 9, 174. [CrossRef]

52. Bai, A.J.; Rai, V.R. Bacterial Quorum Sensing and Food Industry. Compr. Rev. Food Sci. Food Saf. 2011, 10, 183-193. [CrossRef]

53. Liu, Y.; Rousseaux, S.; Tourdot-Maréchal, R.; Sadoudi, M.; Gougeon, R.; Schmitt-Kopplin, P.; Alexandre, H. Wine microbiome: A dynamic world of microbial interactions. Crit. Rev. Food Sci. Nutr. 2017, 57, 856-873. [CrossRef] [PubMed]

54. Blasche, S.; Kim, Y.; Mars, R.; Kafkia, E.; Maansson, M.; Machado, D.; Teusink, B.; Nielsen, J.; Benes, V.; Neves, R.; et al. Emergence of stable coexistence in a complex microbial community through metabolic cooperation and spatio-temporal niche partitioning. bioRxiv 2019, 541870. [CrossRef]

55. Laureys, D.; De Vuyst, L. Microbial species diversity, community dynamics, and metabolite kinetics of water kefir fermentation. Appl. Environ. Microbiol. 2014, 80, 2564-2572. [CrossRef] [PubMed]

56. Hu, J.-B.; Gunathilake, S.; Chen, Y.-C.; Urban, P.L. On the dynamics of kefir volatome. RSC Adv. 2014, 4, 28865. [CrossRef] 
57. Katakura, Y.; Sano, R.; Hashimoto, T.; Ninomiya, K.; Shioya, S. Lactic acid bacteria display on the cell surface cytosolic proteins that recognize yeast mannan. Appl. Microbiol. Biotechnol. 2010, 86, 319-326. [CrossRef]

58. Tada, S.; Katakura, Y.; Ninomiya, K.; Shioya, S. Fed-batch coculture of Lactobacillus kefiranofaciens with Saccharomyces cerevisiae for effective production of kefiran. J. Biosci. Bioeng. 2007, 103, 557-562. [CrossRef]

59. Suharja, A.A.S.; Henriksson, A.; Liu, S.-Q. Impact of Saccharomyces Cerevisiae on Viability of Probiotic Lactobacillus Rhamnosus in Fermented Milk under Ambient Conditions. J. Food Process. Preserv. 2014, 38, 326-337. [CrossRef]

60. Sieuwerts, S.; Bron, P.A.; Smid, E.J. Mutually stimulating interactions between lactic acid bacteria and Saccharomyces cerevisiae in sourdough fermentation. LWT 2018, 90, 201-206. [CrossRef]

61. Ponomarova, O.; Gabrielli, N.; Sévin, D.C.; Mülleder, M.; Zirngibl, K.; Bulyha, K.; Andrejev, S.; Kafkia, E.; Typas, A.; Sauer, U.; et al. Yeast Creates a Niche for Symbiotic Lactic Acid Bacteria through Nitrogen Overflow. Cell Syst. 2017, 5, 345-357.e6. [CrossRef]

62. Stadie, J.; Gulitz, A.; Ehrmann, M.A.; Vogel, R.F. Metabolic activity and symbiotic interactions of lactic acid bacteria and yeasts isolated from water kefir. Food Microbiol. 2013, 35, 92-98. [CrossRef]

63. Liu, M.; Bayjanov, J.R.; Renckens, B.; Nauta, A.; Siezen, R.J. The proteolytic system of lactic acid bacteria revisited: A genomic comparison. BMC Genomics 2010, 11, 36. [CrossRef] [PubMed]

64. Avbelj, M.; Zupan, J.; Raspor, P. Quorum-sensing in yeast and its potential in wine making. Appl. Microbiol. Biotechnol. 2016, 100, 7841-7852. [CrossRef] [PubMed]

65. Albergaria, H.; Francisco, D.; Gori, K.; Arneborg, N.; Gírio, F. Saccharomyces cerevisiae CCMI 885 secretes peptides that inhibit the growth of some non-Saccharomyces wine-related strains. Appl. Microbiol. Biotechnol. 2010, 86, 965-972. [CrossRef] [PubMed]

66. Albergaria, H.; Arneborg, N. Dominance of Saccharomyces cerevisiae in alcoholic fermentation processes: Role of physiological fitness and microbial interactions. Appl. Microbiol. Biotechnol. 2016, 100, 2035-2046. [CrossRef] [PubMed]

67. Fiocco, D.; Longo, A.; Arena, M.P.; Russo, P.; Spano, G.; Capozzi, V. How probiotics face food stress: They get by with a little help. Crit. Rev. Food Sci. Nutr. 2019, 1-29. [CrossRef] [PubMed]

68. Vardjan, T.; Mohar Lorbeg, P.; Čanžek Majhenič, A. Stability of prevailing lactobacilli and yeasts in kefir grains and kefir beverages during ten weeks of propagation. Int. J. Dairy Technol. 2018, 71, 51-60. [CrossRef]

69. Chen, M.-J.; Tang, H.-Y.; Chiang, M.-L. Effects of heat, cold, acid and bile salt adaptations on the stress tolerance and protein expression of kefir-isolated probiotic Lactobacillus kefiranofaciens M1. Food Microbiol. 2017, 66, 20-27. [CrossRef] 